\title{
USO DA rbST NO DIA DO ESTRO EM RECEPTORAS DE EMBRIÃO BOVINO CRIOPRESERVADO
}

\author{
Eduardo Paulino da Costa $^{1}$, Paulo Alexandre Fernandes Marques ${ }^{2}$, CARlos Antônio de

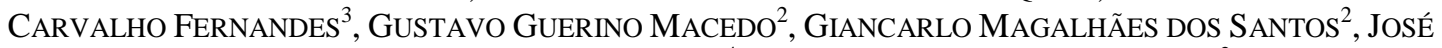 \\ Rogério Moura de Almeida Neto ${ }^{4}$, EMÍlio CÉSAR MARTINS PEREIRA ${ }^{2}$ \\ ${ }^{1}$ Professor Associado da Universidade Federal de Viçosa, Viçosa, MG. epcosta@ufv.br \\ ${ }^{2}$ Pós-graduando da Universidade Federal de Viçosa, Viçosa, MG. \\ ${ }^{3}$ Professor Doutor da Universidade José do Rosário Vellano, Alfenas, MG. \\ ${ }^{4}$ Professor Mestre do Centro de Ensino Superior de Valença, Valença, MG.
}

\begin{abstract}
Estudou-se o efeito da administração de duas doses de rbST (250 e $500 \mathrm{mg}$ ) no dia do estro em receptoras de embrião bovino criopreservado na taxa de gestação e na concentração sérica de progesterona. No experimento I, 44 receptoras foram distribuídas em dois tratamentos: $\mathrm{T} 1(\mathrm{n}=$ 22 , controle) e $\mathrm{T} 2(\mathrm{n}=22)$, recebendo a administração subcutânea de $250 \mathrm{mg}$ de $\mathrm{rbST}$. No experimento II, 71 receptoras foram distribuídas em: $\mathrm{T} 1(\mathrm{n}=31$, controle $)$ e T2(n = 40), recebendo $500 \mathrm{mg}$ de rbST. Os diagnósticos de gestação foram realizados 30 dias após o estro. As taxas de gestação não diferiram entre tratamentos em ambos os experimentos (40,9\%(T1) vs 50,0\%(T2) e
\end{abstract}

48,4\%(T1) vs 52,5\%(T2) para os experimentos I e II, respectivamente). As concentrações séricas de progesterona (ng/mL de plasma), obtidas nas amostras de sangue coletadas no dia da inovulação, não diferiram entre tratamentos, sendo $5,92 \pm 0,62$ (T1) vs $5,77 \pm 0,48(\mathrm{~T} 2)$ e $4,94 \pm 0,54$ (T1) vs $4,77 \pm 0,51$ (T2) para os experimentos I e II, respectivamente. Esses resultados indicam que a administração de 250 ou $500 \mathrm{mg}$ de rbST, no dia do estro, não proporciona incremento tanto na taxa de gestação como na concentração sérica de progesterona de receptoras de embrião bovino criopreservado.

PALAVRAS-CHAVE: bovino; receptora de embrião; taxa de gestação.

\section{USE OF rbST ON ESTRUS DAY IN RECIPIENTS OF FROZEN BOVINE EMBRYOS}

\section{ABSTRACT}

The aim of this study was to evaluate the effects of the administration of 250 and $500 \mathrm{mg}$ of rbST to bovine recipients of frozen embryos on estrus day on pregnancy rate and on serum progesterone concentration. In experiment $\mathrm{I}, 44$ recipients were allotted into two treatments: $\mathrm{T} 1(\mathrm{n}=22$, control $)$ and $T 2(\mathrm{n}=22)$, in which animals received $250 \mathrm{mg}$ rbST subcutaneously. In experiment II, 71 recipients were allotted in: $\mathrm{T} 1(\mathrm{n}=31$, control) and $\mathrm{T} 2(\mathrm{n}=40)$, in which animals received 500 $\mathrm{mg}$ rbST. Pregnancy diagnosis occurred 30 days after estrus. Pregnancy rates did not differ between treatments in both experiments: $40.9 \%(\mathrm{~T} 1)$ vs $50.0 \%$ (T2) and

KEYWORDS: bovine; embryo recipients; pregnancy rate.
48.4\%(T1) vs 52.5\%(T2) in experiments I and II, respectively. Likewise, the average progesterone concentration (ng/mL plasma) obtained from blood collection samples on the embryo transfer day did not show differences between the treatments: $5.29 \pm 0.62$ (T1) vs. $5.77 \pm 0.48(\mathrm{~T} 2)$ and $4.94 \pm 0.54(\mathrm{~T} 1)$ vs. $4.77 \pm$ $0.51(\mathrm{~T} 2)$ in experiments $\mathrm{I}$ and II, respectively. These results demonstrate that the administration of 250 or 500 $\mathrm{mg}$ rbST on estrus day does not increase pregnancy rate nor the serum progesterone concentration of frozen bovine embryo recipients. 


\section{INTRODUÇÃO}

O desenvolvimento e a utilização de biotécnicas ligadas à reprodução animal são condições indispensáveis para a elevação da eficiência reprodutiva nos rebanhos e rentabilidade das empresas rurais. Dentre as biotecnologias, a transferência de embriões (TE) tem assumido grande importância no cenário atual, como incremento na multiplicação de material genético.

Dentre os principais problemas associados ao avanço da técnica de TE, pode-se citar o alto custo no manejo das receptoras (FERNANDES, 1999). No intuito de minimizar os custos, tem-se aumentado as pesquisas relacionadas à criopreservação de embriões. A congelação é importante, quando não se dispõe de muitas fêmeas aptas para a inovulação, além de facilitar a comercialização e possibilitar a formação de bancos de germoplasma.

Entretanto, essa tecnologia resulta em baixas taxas de gestação (ARAÚJO et al., 2005). Essa menor eficiência na concepção deve-se ao fato de o resfriamento e congelamento dos embriões causar injúrias celulares, comprometendo o desenvolvimento do concepto e a secreção de fatores fundamentais para $\mathrm{o}$ reconhecimento materno da gestação. Entre os fatores que atuam no reconhecimento do embrião pelo organismo materno, destaca-se o interferon-tau (INF- $\tau$ ) (THATCHER et al., 2001).

A ação do INF- $\tau$ para a manutenção da gestação consiste em inibir os fatores relacionados com a luteólise (THATCHER et al., 2001), com seu efeito sendo tão importante que o atraso e/ou mesmo quantidades insuficientes de sua secreção podem ser responsáveis pela morte embrionária precoce (ARNOLD et al., 2000), a qual é reconhecida como a maior causa de subfertilidade na espécie bovina (SREENAN et al., 2001).

No intuito de prevenir maiores perdas embrionárias, BILBY et al. (1999) sugeriram que a administração de somatotropina bovina recombinante (rbST) incrementa a secreção de bST e IGF-I. Esse processo pode desencadear uma série de eventos como aumento da atividade secretória das glândulas endometriais e da taxa de clivagem, resultando em maior número de células trofoblásticas (BLOCK et al., 2003) e desenvolvimento inicial (MOREIRA et al., 2002), incrementando a secreção de INF- $\tau$ (BILBY et al., 2006) e, consequentemente, diminuindo as perdas embrionárias (ARNOLD et al., 2000).

O objetivo do presente trabalho foi verificar o efeito da administração de 250 e 500 mg de rBST no dia do estro em receptoras de embriões criopreservados sobre a taxa de gestação e concentração sérica de progesterona $\left(\mathrm{P}_{4}\right)$.

\section{MATERIAL E MÉTODOS}

Dois experimentos foram realizados na região de Alfenas - MG, situada na latitude sul $21^{\circ}$ 25 ' 45" e longitude oeste $45^{\circ}$ 56'50". Foram utilizadas 115 receptoras de embrião mestiças (Nelore x Angus ou Brangus), sendo vacas (com no mínimo 4 meses pós-parto) e novilhas. As fêmeas possuiam escore de condição corporal $\geq 3$ (escala de um a cinco, FERREIRA, 1990) e peso corporal acima de $350 \mathrm{~kg}$, previamente selecionadas por exame ginecológico e observadas por dois ciclos estrais completos. As receptoras foram alojadas em piquetes em regime de pastejo, predominantemente de capim-braquiária (Brachiaria brizanta), com fornecimento de sal mineral e água ad libitum. As fêmeas se encontravam entre o sétimo e $17^{\circ}$ dia do ciclo estral e receberam a aplicação de $0,53 \mathrm{mg}$ de cloprostenol sódico (Ciosin ${ }^{\circledR} ; \quad$ Schering-Plough Brasil Ltda; Brasil), via intra-muscular. A detecção do estro dos animais foi realizada visualmente, com o auxílio de rufiões, duas vezes ao dia (início da manhã e final da tarde), por um período mínimo de 30 minutos.

Os animais que apresentaram estro foram distribuídos em dois experimentos. No experimento $\mathrm{I}$ as receptoras foram aleatoriamente divididas em dois tratamentos: o T1-Controle $(\mathrm{n}=22)$ e no T2 $(\mathrm{n}$ = 22), $250 \mathrm{mg}$ de rbST IM no dia do estro. As fêmeas do experimento II foram também distribuídas, aleatoriamente, em dois tratamentos: o T1-Controle $(n=31)$ foi usado como controle. No T2 $(n=40)$, receberam $500 \mathrm{mg}$ de rbST no dia do estro. No sétimo dia, as receptoras foram inovuladas pelo método transcervical com embriões criopreservados de qualidade excelente ou boa (IETS, 1999). Foram inovulados apenas embriões que apresentavam a mesma qualidade quando descongelados.

As coletas de sangue para dosagem de $\mathrm{P}_{4}$ foram realizadas no momento das inovulações dos embriões, em tubos vacuolizados de $10 \mathrm{~mL}$, sem anticoagulante, via punção da artéria ou veia coccígeas e estocados em isopor à temperatura de 5 a $8^{\circ} \mathrm{C}$. Após a centrifugação a $1700 \mathrm{G}$ por 10 minutos, os soros foram acondicionados em microtubos, identificados e estocados à temperatura de $-20^{\circ} \mathrm{C}$. As amostras de soro sanguíneo foram submetidas à análise de $\mathrm{P}_{4}$ utilizando-se o kit 
comercial de radioimunoensaio (RIA) em fase sólida no Laboratório de Preparo de Amostras e Radioimunoensaio da Empresa Brasileira de Pesquisa Agropecuária (EMBRAPA) - Gado de Leite (Centro Nacional de Pesquisa de Gado de Leite - CNPGL). Os diagnósticos de gestação foram realizados 30 dias após o estro das receptoras, por meio de exames ultra-sonográficos via transretal. As taxas de gestação foram arranjadas em tabelas de contingência e, posteriormente, submetidas à análise pelo teste de Qui-quadrado, a $5 \%$ de probabilidade de erro. Para análise das concentrações séricas de $\mathrm{P}_{4}$, utilizou-se o programa
SAEG 8.0 (2000). Os dados foram submetidos aos testes de normalidade (Lillefors) e homocedasticidade (Cochram e Bartlet), e posteriormente analisados utilizando-se o teste $\mathrm{F}$, adotando-se $5 \%$ de probabilidade.

\section{RESULTADOS E DISCUSSÃO}

No experimento I, as taxas de gestação dos animais que receberam embrião criopreservado foram de 40,9\% (T1) e 50,0\% (T2) (Tabela 1), indicando que o uso de $250 \mathrm{mg}$ de rbST não influenciou na taxa de gestação $(\mathrm{P}>0,05)$.

Tabela 1 - Número de animais e taxas de gestação em receptoras de embrião criopreservado, tratadas ou não com $250 \mathrm{mg}$ de rbST no dia do estro

\begin{tabular}{lccc}
\hline \multirow{2}{*}{ Tratamentos } & $\mathrm{N}$ & Gestantes & Não Gestantes \\
\cline { 3 - 4 } & & $\%$ & $\%$ \\
\hline Controle (T1) & 22 & $40,9(9 / 22)$ & $59,1(13 / 22)$ \\
$250 \mathrm{mg} \mathrm{rbST}(\mathrm{T} 2)$ & 22 & $50,0(11 / 22)$ & $50,0(11 / 22)$ \\
\hline
\end{tabular}

Não houve diferença entre tratamentos $(\mathrm{P}>0,05)$ pelo teste de Qui-quadrado.

As concentrações médias de $\mathrm{P}_{4}$ séricas para as receptoras de embrião congelado foram similares tanto para as gestantes quanto para as não gestantes (Tabela 2), não havendo diferença $(\mathrm{P}>0,05)$. As concentrações séricas de $\mathrm{P}_{4}$ entre os grupos controle (T1) e $250 \mathrm{mg}$ de $\mathrm{rbST}$ (T2), independentemente do estado gestacional, não foram diferentes $(\mathrm{P}>0,05)$, conforme demonstrado na Tabela 2.

Tabela 2 - Concentração média de progesterona sérica $(\mathrm{ng} / \mathrm{mL})$ no dia da inovulação em receptoras gestantes, não gestantes e independente do estado gestacional, tratadas ou não com $250 \mathrm{mg}$ de rbST

\begin{tabular}{lccc}
\hline \multirow{2}{*}{ Tratamento } & \multicolumn{2}{c}{ Progesterona $\left(\mathrm{P}_{4}\right)(\mathrm{ng} / \mathrm{mL})$} \\
\cline { 2 - 4 } & Gestantes & Não Gestantes & Independente do estado gestacional \\
\hline Controle (T1) & $5,72 \pm 1,10$ & $6,04 \pm 0,87$ & $5,92 \pm 0,62$ \\
250 mg rbST (T2) & $5,46 \pm 0,67$ & $6,08 \pm 0,67$ & $5,77 \pm 0,48$ \\
\hline
\end{tabular}

Não houve diferença entre tratamentos $(\mathrm{P}>0,05)$ pelo teste $\mathrm{F}$.

No experimento II, as taxas de gestação dos animais que receberam embrião criopreservado foram de 48,4\% (T1) e 52,5\% (T2) (Tabela 3), indicando que o uso de $500 \mathrm{mg}$ de rbST não influenciou na taxa de gestação $(\mathrm{P}>0,05)$.

Tabela 3 - Número de animais e taxas de gestação em receptoras de embrião criopreservado, tratadas ou não tratadas com $500 \mathrm{mg}$ de rbST no dia do estro

\begin{tabular}{lccc}
\hline \multirow{2}{*}{ Tratamentos } & $\mathrm{N}$ & Gestantes & Não Gestantes \\
\cline { 3 - 4 } & & $\%$ & $\%$ \\
\hline Controle (T 1) & 31 & $48,4(15 / 31)$ & $51,6(16 / 31)$ \\
500 mg rbST (T 2) & 40 & $52,5(21 / 40)$ & $47,5(19 / 40)$ \\
\hline
\end{tabular}

Não houve diferença entre tratamentos $(\mathrm{P}>0,05)$ pelo teste de Qui-quadrado. 
As concentrações médias de progesterona sérica para as receptoras de embrião congelado foram similares tanto para as gestantes quanto não gestantes (Tabela 4), não sendo observada diferença
( $\mathrm{P}>0,05)$. Da mesma forma, as concentrações de $\mathrm{P}_{4}$ entre os grupos controle (T1) e $500 \mathrm{mg}$ de rbST (T2), independentemente do estado gestacional, não foram diferentes ( $\mathrm{P}>0,05)$, como demonstrado na Tabela 4.

Tabela 4 - Concentrações médias de progesterona sérica $(\mathrm{ng} / \mathrm{mL})$ no dia da inovulação em receptoras gestantes, não gestantes ou independente do estado gestacional, tratadas ou não com 500 mg de rbST

\begin{tabular}{lccc}
\hline \multirow{2}{*}{ Tratamento } & \multicolumn{3}{c}{ Progesterona $\left(\mathrm{P}_{4}\right)(\mathrm{ng} / \mathrm{mL})$} \\
\cline { 2 - 4 } & Gestantes & Não Gestantes & Independente do estado gestacional \\
\hline Controle (T1) & $6,17 \pm 0,86$ & $4,01 \pm 0,74$ & $4,94 \pm 0,54$ \\
$500 \mathrm{mg}$ rbST (T2) & $4,94 \pm 0,58$ & $4,48 \pm 0,74$ & $4,77 \pm 0,51$ \\
\hline
\end{tabular}

Não houve diferença entre tratamentos $(\mathrm{P}>0,05)$ pelo teste $\mathrm{F}$.

Em ambos os experimentos não foi encontrada influência na taxa de gestação entre os grupos tratados e controles $(\mathrm{P}>0,05)$. Esses resultados diferem dos obtidos por MOREIRA et al. (2002), os quais trabalharam com vacas lactantes e submetidas à terapia de $500 \mathrm{mg}$ de rbST um dia pós-estro e, posteriormente, a cada 14 dias (três a quatro aplicações). Esses autores obtiveram taxa de gestação $17,7 \%$ superior $(\mathrm{P}<0,05)$ para o grupo de receptoras tratadas com bST.

Segundo MOREIRA et al. (2002), a aplicação de rbST pode incrementar as concentrações de bST e IGF-1 circulante, acelerando o desenvolvimento embrionário e aumentando o número de células trofoblásticas, resultando em incremento na secreção de IFN- $\tau$ pelo embrião. Essa condição foi verificada por THATCHER et al. (2006), os quais observaram aumento na concentração de IFN- $\tau$ no fluido uterino após a administração de 500mg de rbST.

KAIDI et al. (1999) afirmaram que os danos causados pelo processo de criopreservação, que ocorrem no trofoderma e na massa celular interna, são responsáveis pela redução no número de células trofoblásticas do embrião e fragmentação da membrana nuclear (SAHA \& SUZUKI, 1997; VAJTA et al., 1997), podendo ocorrer deficiência na expressão do gene que codifica a produção de INF- $\tau$ (LONERGAN et al., 2003).

Essas lesões são decorrentes da formação de cristais de gelo intra e extracelular (VAJTA et al., 1997) e dos efeitos osmóticos e tóxicos dos crioprotetores durante o período de desidratação e reidratação embrionária (SAHA \& SUZUKI, 1997). Desse modo, a secreção de IFN- $\tau$ pode ser diminuída (KRISTINA et al., 2001), comprometendo os sinais do reconhecimento materno da gestação (LONERGAN et al., 2003), possibilitando a elevação da taxa de mortalidade embrionária (ARNOLD et al., 2000).

Portanto, apesar do efeito benéfico da rbST na produção de IFN- $\tau$ pelo embrião, é provável que as lesões promovidas nas células trofoblásticas durante o processo de criopreservação tenham resultado em baixa capacidade para elevar a síntese de IFN- $\tau$ pelo embrião quando as vacas são tratadas com rbST. ARAÚJO et al. (2005) corroboram essa afirmação pois encontraram uma menor concentração desse interferon em embriões previamente criopreservados e cultivados in vitro, quando comparado com embriões não criopreservados.

Segundo MANN \& LAMMING (2001), o aumento na concentração de $\mathrm{P}_{4}$ pode ser um fator importante para o aumento da taxa de gestação, pois maiores quantidades desse esteróide poderiam exercer função luteoprotetora e prevenir a regressão lutea. Nesse contexto, a rbST potencializa a secreção de bST e IGF-1, desencadeando uma cascata de eventos (BILBY et al., 1999) que, de forma direta ou indireta, pode acelerar o crescimento do corpo lúteo e a secreção de $\mathrm{P}_{4}$ durante a fase luteínica do ciclo estral (LUCY et al., 1995; BORGES et al., 2001).

As concentrações de $\mathrm{P}_{4}$ sérica em receptoras no dia da inovulação não foram diferentes entre os animais tratados ou não com rbST (Tabelas 2 e 4). Resultados similares aos encontrados no presente estudo foram obtidos por DROST et al. (1999), ao trabalharem com vacas lactantes. Outras pesquisas também não evidenciaram incremento na concentração sérica de $\mathrm{P} 4$ com a administração de $250 \mathrm{mg}$ (HAAS, 2004) ou $500 \mathrm{mg}$ de rbST no dia do estro (STARBUCK et al., 2006; MARQUES et al., 2009) ou de $500 \mathrm{mg}$ de rbST no quinto dia do ciclo estral (FONSECA et al., 2001). Segundo FOXCROFT et al. (2000) e THATCHER et al. (2006), a somatotropina incrementa o metabolismo e 
o fluxo sanguíneo hepático, o qual eleva o clearance hormonal, impedindo que sejam mantidas elevadas concentrações de $\mathrm{P}_{4}$ no plasma (LUCY et al., 1994).

\section{CONCLUSÕES}

A administração de 250 ou $500 \mathrm{mg}$ de rbST no dia do estro em receptoras inovuladas com embrião congelado não influencia na concentração sérica de progesterona e nem na taxa de gestação.

\section{AGRADECIMENTOS}

\section{À FAPEMIG pelo apoio financeiro do projeto. \\ COMITÊ DE ÉTICA E BIOSSEGURANÇA}

Este Projeto de Pesquisa foi aprovado pela Comissão de Bioética do Departamento de Medicina Veterinária da Universidade Federal de Viçosa.

\section{REFERÊNCIAS}

ARAÚJO, M.C.C. VALE FILHO, V.R.; FERREIRA, A.M.; SÁ, W.FBARRETO FILHO, ; J.B.; CAMARGO, L.S.A; SERAPIÃO, R.V.; SILVA, M.V.G.B. Secreção de interferon-tau em embriões bovinos produzidos in vitro frescos e congelados. Arquivo Brasileiro de Medicina Veterinária e Zootecnia, v.57, p.751-756, 2005. Disponível

em:

<http://www.scielo.br/scielo.php?script=sci_arttext\&pid=S 0102-09352005000600008\&lng=pt\&nrm=iso > Acesso em: 12 mai. 2009. doi: 10.1590/S0102-09352005000600008.

ARNOLD, D.R; BINELLIA, M.; VONKB, J.; ALEXENKOC, A.P.; DROSTA, M.; WILCOXA, C.J.; THATCHERA, W.W. Intracellular regulation of endometrial PGF2 $\alpha$ production in dairy cows during early pregnancy and following treatment with recombinant interferon- $\tau$. Domestic Animal Endocrinology, v.18, p.199-216, 2000. Disponível em: $<$ http://www.sciencedirect.com/science? ob=ArticleURL\& udi=B6T62-

400 WHWJ $4 \&$ user $=687369 \&$ rdoc $=1 \&$ fmt $=\&$ orig $=$ sea $\underline{\text { rch \& sort }=\mathrm{d} \& \text { docanchor }=\& \text { view }=\mathrm{c} \& \text { acct }=\mathrm{C} 000037901}$ $\&$ \& version $=1 \&$ urlVersion $=0 \&$ userid $=687369 \& \mathrm{md} 5=\mathrm{e} 60$ 85571ec0f1279606604141e43ef51> Acesso em: $17 \mathrm{dez}$. 2009. doi:10.1016/S0739-7240(99)00079-X

BILBY， C.R.; BADER， A， J.F.; SALFEN， B.E.; YOUNGQUIST, R.S.; MURPHY, C.N.; GARVERICK, H.A.; CROOKER, B.A.; LUCY, M.C. Plasma GH, IGF-1, and conception rate in cattle treated with low doses of recombinant bovine GH. Theriogenology, v.51, p.12851296, $1999 . \quad$ Disponível em: $<$ http://www.sciencedirect.com/science? ob=ArticleURL\& udi=B6TCM-3X6BPM2-

$7 \&$ user $=687369 \&$ rdoc $=1 \&$ fmt $=\&$ orig $=$ search $\&$ sort $=$ $\mathrm{d} \&$ docanchor $=\&$ view $=\mathrm{c} \&$ \&acct $=\mathrm{C} 000037901 \&$ \&ersion $=$
$1 \&$ urlVersion $=0 \&$ userid $=687369 \& \operatorname{md} 5=78 \mathrm{adfb} 27 \mathrm{~d} 3077$ d6cf5c3ebe611913a5e> Acesso em: 07 Abr. 2009. doi:10.1016/S0093-691X(99)00072-2

BILBY, T.R.; SOZZI, A.; LOPEZ, M.M.; SILVESTRE, F.T.; EALY, A.D.; STAPLES, C.R.; THATCHER, W.W. Pregnancy, bovine somatotropin, and dietary o 3 fatty acids in lactating dairy cows. I. Ovarian, conceptus, and growth hormone-insulin-like growth factor system responses. Journal Dairy Science, v.89,n.9, p.3360-3374, 2006.

BLOCK, J.; DROST, M.; MONSON, R. L.; RUTLEDGE, J. J.; RIVERA, R. M.; PAULA-LOPES, F. F.; OCON, O. M.; KRININGER, C. E.; LIU, J.; HANSEN, P. J. Use of insulin-like growth factor-I during embryo culture and treatment of recipients with gonadotropin-releasing hormone to increase pregnancy rates following the transfer of in vitro-produced embryos to heat-stressed, lactating cows. Journal of Animal Science, v.81,n. 6, p.1590-1602, 2003.

BORGES, Á. M.; TORRES, C. A. A.; RUAS, J. R. M.; ROCHA JÚNIOR, V. R.; CARVALHO, G. R. de; BORGES, J. C. Concentração plasmática de progesterona e metabólitos lipídicos em novilhas mestiças tratadas ou não com hormônio de crescimento e superovuladas. Revista Brasileira de Zootecnia, v.30, n.6, p.1689-1696, 2001.

DROST, M.; AMBROSE, J.D.; THATCHER, M.J.; CANTRELL, C.K.; WOLFSDORF, K.E.; HASLER, J.F.; THATCHER, WW. Conception rates after artificial insemination or embryo transfer in lactating dairy cows during summer in Florida. Theriogenology, v.52, n.7, p.1161-1167, 1999.

FERNANDES, C.A.C. Inovulações não cirúrgicas e taxa de gestação de receptoras de embrião. Arquivo Brasileiro de Medicina Veterinária e Zootecnia, v.51, p.263-266, 1999.

FERREIRA, A.M. Efeito da amamentação e do nível nutricional na atividade ovariana de vacas mestiças leiteiras. 1990. 134p. Tese (Doutorado) - Universidade Federal de Viçosa, Viçosa, 1990.

FONSECA, J.F.; SILVA FILHO, J.M.; PINTO NETO, A.; PALHARES, M.S.; RUAS, J.R.M. Taxas de gestação de novilhas receptoras submetidas à administração de $\mathrm{rbST}$, GnRH ou hCG no quinto dia do ciclo estral. Arquivo Brasileiro de Medicina Veterinária e Zootecnia, v.53, 2001. Disponível em: < http://www.scielo.br/scielo.php?script=sci arttext\&pid=S0 $10209352001000400013 \& \operatorname{lng}=$ en $\&$ nrm=iso $>$ Acesso em: 20 nov. 2009. doi: 10.1590/S0102-09352001000400013

FOXCROFT, G.; ALMEIDA, F.; AHERNE, F. Management of the gilt and first parity sow. In: SIMPÓSIO INTERNACIONAL DE REPRODUÇÃO ANIMAL E INSEMINAÇÃO ARTIFICIAL EM SUÍNOS, 7., 2000, Foz do Iguaçu. Anais. Foz do Iguaçu 2000. p.131-145.

HAAS, G.T.S. Taxa de gestação e concentração sérica de progesterona em receptoras de embrião bovino tratadas com somatotropina recombinante bovina (rbST). 2004. 38p. Dissertação (Mestrado) - Universidade 
Federal de Viçosa, Viçosa, 2004. Disponível em: http://www.dominiopublico.gov.br/

pesquisa/DetalheObraForm.do?select_action $=\&$ co_obra $=1$ 59652

IETS (International Embryo Transfer Society) Manual da Sociedade Internacional de Transferência de Embriões, Savoy, Illinois, USA, 1999, 180p.

KAIDI, S.; VAN LANGENDONCKT, A.; MASSIP, A.; DESSY, F.; DONNAY, I. Cellular alteration after dilution of cryoprotective solutions used for the vitrification of in vitro-produced bovine embryos. Theriogenology, v.52, p.515-525, 1999.

KRISTINA, J.D. Trophoblast interferon and pregnancy. Reproduction, v.121, p.41-49, 2001.

LONERGAN, P.; RIZOS, D.; GUTIÉRREZ-ADÁN, A.; MOREIRA, P.M.; PINTADO, B.; DE LA FUENTE, J.; BOLAND, M.P.Temporal divergence in the pattern of messenger RNA expression on bovine embryos cultured from the zygote to blastocyst stage in vitro or in vivo. Biology Reproduction, v.69, p.1424-1431, 2003. Disponível em: http://www.biolreprod.org/content/69/4/1424.long>. Acesso em: 20 Nov 2009. doi: 10.1095/ biolreprod.103.018168

LUCY, M.C.; CURRAN, T.L.; COLLIER, R.J.; COLE, W.J.Extended function of the corpus luteum and advanced follicular development in heifers treated with bovine somatotropin. Theriogenology, v.41, p.561-572, 1994. Disponível em:

http://www.sciencedirect.com/science?_ob=ArticleURL\&_ udi=B6TCM-49NPPBC-

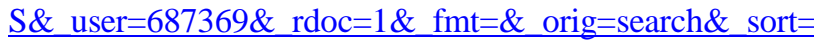
$\mathrm{d} \&$ docanchor $=\&$ view $=\mathrm{c} \&$ acct $=\mathrm{C} 000037901 \&$ version $=$ $1 \&$ urlVersion $=0 \&$ userid $=687369 \& \mathrm{md} 5=\mathrm{bd} 5405 \mathrm{aab} 40 \mathrm{f} 1$ 59794a9a8f84e1e2f7c>. Acesso em: 25 nov 2009. doi:10.1016/0093-691X(94)90091-V

LUCY, M.C.; THATCHER, W.W.; COLLIER, R.J.; SIMMEN, F.A.; KO, Y.; SAVIO, J.D.; BADINGA, L. Effects of somatotropin on the conceptus, uterus, and ovary during maternal recognition of pregnancy in cattle. Domestic Animal Endocrinology, v.12, p.73-82, 1995. Disponível

em:

$<$ http://www.sciencedirect.com/science? ob=ArticleURL\& udi=B6T62-3XX6TFT-

$13 \&$ user $=687369 \&$ rdoc $=1 \&$ fmt $=\&$ orig $=$ search \& sort $=\mathrm{d} \&$ docanchor $=\&$ view $=\mathrm{c} \&$ acct $=\mathrm{C} 000037901 \&$ version $=1 \&$ urlVersion $=0 \&$ userid $=687369 \& \mathrm{md} 5=\mathrm{dc} 4 \mathrm{eb} 2 \mathrm{a} 15 \mathrm{c} 7 \mathrm{~b}$ 6b03cb75be6e85e7a3e2. Acesso em: 20 Nov 2009. doi:10.1016/0739-7240(94)00010-X

MANN, G.E.; LAMMING, G.E. Relationship between maternal endocrine environment, early embryo development and inhibition of luteolytic mechanism in cows. Reproduction, v.121, p.175-180, 2001. Disponível em:

<http://www.reproduction- online.org/cgi/reprint/121/1/175>. Acesso em: 22 Nov 2009.

MARQUES, P. A. F.; COSTA, E. P. da; FERNANDES, C. A. de C.; PAULA, T. A. R. de; ALMEIDA NETO, J. R. M. de; dos SANTOS, G. M.Inovulação de embriões bovinos recém-colhidos em receptoras tratadas com rbST no dia do estro. Revista Brasileira de Zootecnia, v.38, p.462-466, 2009.

MOREIRA, F.; BADINGA, L.; BURNLEY, C.; THATCHER, W.W. Bovine somatotropin increases embryonic development in superovulated cows and improves post-ransfer pregnancy rates when given to lactating recipient cows. Theriogenology, v.57, p.13711387,2002

SAHA, S.; SUZUKI, T. Vitrification of in vitro produced bovine embryos at different ages using one and three-step addition of cryoprotective additives. Reproduction Fertility Development, v.9, p.741-746, 1997.

SREENAN, J.M. Embryo survival rate in cattle: a major limitation to the achievement of high fertility. Animal Science, v.1, p.93-104, 2001.

STARBUCK, M. J.; INSKEEP, E. K.; DAILEY, R. A. Effect of a single growth hormone (rbST) treatment at breeding on conception rates and pregnancy retention in dairy and beef cattle. Animal Reproduction Science, v.93, p.349-359, 2006. Disponível em < http://www.sciencedirect.com/science?_ob=ArticleURL\&_ udi=B6T43-4H5MYM3-

$1 \& \_$user $=687369 \& \_$rdoc $=1 \&$ fmt $=\&$ \&orig $=$ search \&_sort $=$ d\&_docanchor $=\&$ view $=$ c $\& \_a c c t=C 000037901 \& \_v e r s i o n=$ $1 \&$ urlVersion $=0 \&$ userid $=687369 \& \mathrm{md} 5=\mathrm{a} 2 \mathrm{a} 1063 \mathrm{c} 7 \mathrm{a} 959$ 0ec4c2d84234ef5a1f7>. Acesso em 20 nov 2009. doi:10.1016/j.anireprosci.2005.08.010

THATCHER, W.W.; BILBY, T.R.; BARTOLOME, J.A.; SILVESTRE, F.; STAPLES, C.R.; SANTOS, J.E. Strategies for improving fertility in the modern dairy cow. Theriogenology, v.65, p.30-44, 2006.

THATCHER, W.W.; MOREIRA, F.; SANTOS, J.E.P.; MATTOS, R.C.; LOPES, F.L.; PANCARCI, S.M.; RISCO, C.A. Effects of hormonal treatments of reproductive performance and embryo production. Theriogenology, v.55, p.75-89, 2001.

UNIVERSIDADE FEDERAL DE VIÇOSA - UFV. Sistema de análise estatística e genética - SAEG. Versão 8.0. Viçosa, MG: 2000. 142p.

VAJTA, G.; HYTTEL, P.; CALLESEN, H. Morphological changes of in vitro-produced bovine blastocysts after virification, in-straw direct rehydration and culture. Molecular Reproduction Developopment, v.48, p.9-17, 1997. Disponível em: < http://www3.interscience.wiley.com/cgi-

bin/fulltext/54767/PDFSTART $>$. Acesso 20 nov 2009. DOI 0.1002/(SICI)1098-2795(199709)48:1<9::AIDMRD2>3.0.CO;2-N 